УДК 37.035.4

\title{
ФОРМИРОВАНИЕ ПРАВОВОЙ КУЛЬТУРЫ В РОССИИ: ИСТОРИЧЕСКИЕ И СОЦИАЛЬНО-ПОЛИТИЧЕСКИЕ АСПЕКТЫ ПРОБЛЕМЫ
}

\author{
Керимов Александр Алиевич \\ доктор политических наук, доцент \\ профессор кафедры политических наук \\ ФГАОУ ВО «Уральский федеральный \\ Университет им. Б.Н. Ельцина»
}

\begin{abstract}
Аннотация: Актуальность работы определяется важностью правовой культуры в построении правового государства в современной России. Целью работы является выявление исторических и социально-политических факторов, повлиявших на развитие правовой культуры и распространение правовых идей в российском государстве.
\end{abstract}

Ключевые слова: Право, правовая культура, правовое воспитание, правовая идея, правовое государство.

\section{FORMATION OF LEGAL CULTURE IN RUSSIA: HISTORICAL AND SOCIO-POLITICAL ASPECTS OF THE PROBLEM}

\section{Kerimov Alexander Alievich}

\begin{abstract}
The relevance of the work is determined by the importance of legal culture in the construction of the rule of law in modern Russia. The aim of the work is to identify historical and socio-political factors that influenced the development of legal culture and the dissemination of legal ideas in the Russian state.
\end{abstract}

Key words: Law, legal culture, legal education, legal idea, legal state.

Развитие правовой культуры в любом обществе сопровождается процессами государственного строительства. С момента появления первых органов публичной власти возникают и нормы права, направленные на 


\section{ОБЩЕСТВО, ГОСУДАРСТВО, ЛИЧНОСТЬ: ПРОБЛЕМЫ ВЗАИМОДЕЙСТВИЯ В СОВРЕМЕННЫХ УСЛОВИЯХ}

регулирование жизни общества. Правовая культура формировалась под непосредственным влиянием религии, традиций, обычаев общества. На ранних этапах основу правовой культуры составляли религиозные тексты, имеющие силу закона. Средневековый суд совершался именем бога и от его имени, где пытки считались законным способом получения достоверных сведений о совершенных преступлениях. Только впоследствии, благодаря научнотехническому прогрессу, усилиям гуманистов, философов, французской революции, происходят определенные сдвиги в общественном сознании и отношениях, которые привели к формированию правовой культуры в ее современном понимании. Примерно такой же путь проделала на пути своего зарождения, становления и развития российская правовая культура, которая, тем не менее, существенно отличается от западных моделей.

Начальный этап формирования русской правовой культуры можно отнести к эпохе образования древнерусского государства Киевская Русь. В языческую эпоху и последующий период основу правового сознания составляла идея этикоцентризма, суть которой заключается в подчинении права высоким нравственным, а впоследствии религиозным ценностям. Русь, в силу своего географического положения, была оторвана от греко-римской цивилизации и занимала промежуточное положение между Европой и Азией. В ходе государственного строительства Владимир I выбором византийского варианта христианства предопределил цивилизационный вектор развития Руси. Такой выбор не оставлял места для развития, складывания отношений в обществе на основе права и еще больше отдалял Русь от рационалистического понимания его сущности. Если еще была возможность сближения Руси с Европой, то последовавшее татаро-монгольское иго, если не навсегда, то надолго прервало отношения русских земель с Европой, и, как показала дальнейшая история развития русского государства, уничтожило вариативность его развития.

Для православного сознания западноевропейский индивидуалистический идеал правового государства был неприемлемым. В условиях отсутствия национального суверенитета и зарождающихся тенденций деспотизма в политической системе преобладающим в общественном сознании становится понимание права лишь как одного из средств достижения религиознонравственных целей. Соборность, надындивидуальный характер общественных отношений становятся доминантами православного сознания. В этих условиях, 


\section{ОБЩЕСТВО, ГОСУДАРСТВО, ЛИЧНОСТЬ: ПРОБЛЕМЫ ВЗАИМОДЕЙСТВИЯ В СОВРЕМЕННЫХ УСЛОВИЯХ}

под влиянием и других особенностей развития русских земель, исключалась сама возможность внедрения таких ценностей, как индивидуальный успех, стремление к богатству, требующие неукоснительного соблюдения прав человека и собственности. Игнорирование индивидуальных прав привело к конструированию пространства консервативно-патриархальной идеологии, не допускающей формирования гражданина с рационалистической правовой культурой. Если на Западе «договорное сознание, магическое по своей далекой основе, было окружено авторитетом римской государственной традиции и занимало равноправное место рядом с религиозно-авторитарным, то на Руси оно осознавалось как языческое по своей природе, что наложило печать на его общественную оценку» [1, с. 345$]$.

Правовая культура, понимаемая нами как «совокупность знаний правового характера и то, насколько человек осознает, что в повседневной жизни необходимо следовать требованиям норм права» [2, с. 459], характеризуется такими показателями, как «правовая образованность, знание действующего законодательства, наличие минимальных практических навыков и умение пользоваться этими знаниями в конкретной жизненной ситуации, осознанное соблюдение и исполнение требований юридических норм» [3, с. 450]. Правовая культура выполняет не только функцию наследования правовых ценностей, но и как регулятор правового поведения людей предполагает принятие личностью «социальной необходимости, полезности правовых норм, убеждения в их справедливости и ценности» [3, с. 451]. Из этих характеристик правовой культуры следует неутешительный вывод о правовой неорганизованности российского общества. Казалось бы, после избавления от иностранного ига и обретения национального суверенитета, московское государство имеет все возможности для строительства более современной модели управления с учетом интересов всех сословий. В эту эпоху и в будущем, если «западные правители поднимали общество на борьбу через его консолидацию и внутреннюю демократизацию, а русские цари, наоборот, наступали на свободы людей, действовали строго по своей воле, игнорируя внутренние интересы общества; консолидация российского общества для борьбы с внешним врагом происходила через антидемократизацию и концентрацию власти в руках царя-помазанника божьего» [4, с. 62].

Централизованная власть царей, в отличие от Запада, во многом следовала канонам религиозной модели отношений между государством и 


\section{ОБЩЕСТВО, ГОСУДАРСТВО, ЛИЧНОСТЬ: ПРОБЛЕМЫ ВЗАИМОДЕЙСТВИЯ В СОВРЕМЕННЫХ УСЛОВИЯХ}

обществом. Триада главенства «во вселенной - бог, в государстве - царь, в семье - отец» не оставляет места для индивидуальных прав, кроме обязанностей, полной отдачи себя на милость. Власть в сознании человека обретает черты святости и становится истиной. По меткому выражению Ю.М. Лотмана, «распространяя религиозное чувство на государственность, социальная психология такого типа требовала от общества как бы переноса всего семиозиса на царя, который стал символической фигурой, как бы живой иконой... Уделом же остальных членов общества было поведение с нулевой семиотикой, от них требовалась чисто практическая деятельность» [1, с. 345].

Если на Западе проблемы права, правой культуры, правового воспитания населения всегда занимали значительное место в интеллектуальной жизни общества, то в России к этой теме ученые начинают обращаться только в XIX в. В своих трудах правоведы-мыслители, среди которых были К. Д. Кавелин, С.А. Муромцев, М. М. Ковалевский, Л. И. Петражицкий, Б. А. Кистяковский и др., развивали идею о важной воспитательной роли права. В частности, в этой связи заслуживают внимания слова Б. А. Кистяковского, который отмечал, что «право в гораздо большей степени дисциплинирует человека, чем логика и методология, или чем систематические упражнения воли. Право - это по преимуществу социальная система и притом единственная социально дисциплинирующая система. Социальная дисциплина создается только правом; дисциплинированное общество и общество с развитым правовым порядком тождественные понятия» [5, с. 109].

Роль права в духовном и культурном развитии России была незначительной. Право было чуждым элементом для сознания русского человека. Эта культура могла быть имплементирована в сознание индивида благодаря длительному воспитательному процессу, развитию правовых идей, распространению ценностей права через литературу. Однако сложившиеся политические и социально-экономические порядки не способствовали пониманию права как справедливости и свободы не только во внешних проявлениях, но и во внутренних. Правовое воспитание призвано научить человека не только выполнять свои обязанности, но и понимать их необходимость, признавать их. Но в российском государстве массы этого не понимали, а интеллигенция не обладала умением правового воспитания. По словам Б. А. Кистяковского, «она никогда не уважала права, никогда не видела в нем ценности; из всех культурных ценностей право находилось у нее в 


\section{ОБЩЕСТВО, ГОСУДАРСТВО, ЛИЧНОСТЬ: ПРОБЛЕМЫ ВЗАИМОДЕЙСТВИЯ В СОВРЕМЕННЫХ УСЛОВИЯХ}

большом загоне» [5, с. 109]. В этих условиях не могло быть и речи о формировании прочного правосознания и правовой культуры в российском обществе.

Народ с низким уровнем правосознания не способен понимать все преимущества правового государства. На протяжении веков русский человек с его религиозным сознанием и общинностью очерчивал круг своих обязанностей границами своей общины. Все, что находилось за пределами общины, он воспринимал как чуждый ему мир, приносящий ему насилие, принуждение. «Вопиющая несправедливость одной части законов вызывала в нем презрение к другой. Полное неравенство перед судом убило в нем в самом зародыше уважение к законности. Русский, к какому бы классу он ни принадлежал, нарушает закон всюду, где он может сделать это безнаказанно; точно так же поступает правительство. Это тяжело и печально для нашего

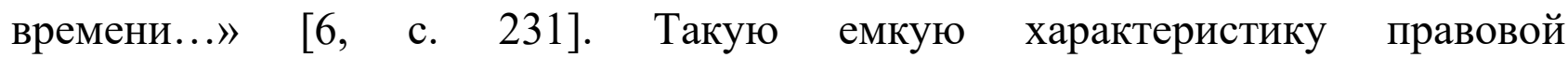
неорганизованности российского общества дает А. И. Герцен.

Таким образом, история развития российского государства свидетельствует о низком уровне правовой культуры граждан и отсутствии интереса к правовым идеям в течение длительного времени. И сегодняшний уровень правовой культуры россиян вряд ли можно считать соответствующим западным стандартам. В то же время очевидно, что построение правового государства невозможно без формирования правовой культуры граждан, что является актуальной задачей, стоящей перед государством и обществом.

\section{Примечание}

Исследование выполнено при финансовой поддержке РФФИ в рамках научного проекта № 20-013-00813\21«Образовательный потенциал медиасферы как пространства развития правовой культуры и культуры прав человека в современной России»

\section{Список литературы}

1. Лотман Ю. М. «Договор» и «вручение себя» как архетипические модели культуры // Лотман Ю. М. Избр. статьи. В 3 т. - Таллин: Александра, 1993. - T. 3. - C. 345-355. 
2. Керимов А. А., Томюк О. Н., Дьячкова М. А., Дудчик А. Ю. Образовательный потенциал блогосферы как фактор формирования правовой культуры человека // Перспективы науки и образ. 2020. № 3 (45). С. 459-474.

3. Дьячкова О.Н. Правовая культура как феномен современности // Науки о культуре в XXI веке: сборник материалов ежегодной конференциисеминара молодых ученых. - М.: РИК, - 2007. - Т. 8. - С. 450-455.

4. Керимов А.А. Парламентаризм как фактор легитимности политической власти в современной России. - Екатеринбург: Изд-во Урал. унта, $-2015 .-304 \mathrm{c}$.

5. Кистяковский Б.А. В защиту права (Интеллигенция и правосознание) // Вехи. Интеллигенция в России. Сб. статей 1909-1910. - М.: Молодая гвардия, - 1991. - С. 109-135.

6. Герцен А.И. Собрание сочинений. В 30-ти т. - М.: Изд-во Акад. наук СССР, 1954-1966. - Т. 7. Произведения 1851-1852 годов. - 1956. - 467 с. 